\title{
Determination of some volatile compounds in fruit spirits produced from grapes (Vitis Vinifera L.) and plums (Prunus domestica L.) cultivars
}

\author{
Vesna Kostik $^{1,}$ *, Biljana Gjorgeska ${ }^{1}$, Bistra Angelovska ${ }^{1}$, Ivona Kovacevska ${ }^{2}$ \\ ${ }^{1}$ Medical Faculty, Department of Pharmacy, University “Goce Delchev”, Shtip, Republic of Macedonia \\ ${ }^{2}$ Medical Faculty, Department of Dental Medicine, University “Goce Delchev”, Shtip, Republic of Macedonia
}

Email address:

vesna2mk@yahoo.com(V. Kostik), biljana.gorgeska@ugd.edu.mk (B. Gjorgeska), bistra.angelovska@ugd.edu.mk (B. Angelovska), ivona.kovacevska@ugd.edu.mk (I. Kovacevska)

\section{To cite this article:}

Vesna Kostik, Biljana Gjorgeska, Bistra Angelovska, Ivona Kovacevska. Determination of Some Volatile Compounds in Fruit Spirits Produced from Grapes (Vitis Vinifera L.) and Plums (Prunus domestica L.) Cultivars. Science Journal of Analytical Chemistry.

Vol. 2, No. 4, 2014, pp. 41-46. doi: 10.11648/j.sjac.20140204.12

\begin{abstract}
Fruit spirits contain a large array of volatile compounds among which the important role from toxicological aspect besides ethanol has methanol, aliphatic esters and fusel alcohols. This study evaluates the content of ethanol, ethyl acetate, methanol, isopropyl alcohol (2-propanol), $n$-propyl alcohol (propan-l-ol), isobutyl alcohol (2-methylpropan-1-ol), $n$-butyl alcohol (1-butanol), isoamyl alcohol (3-methyl-1-butanol) and $n$-amyl alcohol (pentan-1-ol) in different grapes and plum brandies industrially produced at Republic of Macedonia. Gas chromatography (GC) with flame ionization detection (FID) was applied for the characterization of all investigated volatile compounds. The obtained results revealed that the highest methanol content was present in the samples of plum brandy, which is mainly due to the higher content of pectin in the raw material. The most important higher alcohols of grape and plum brandies were found to be: $n$-propyl alcohol, isobutyl alcohol and isoamyl alcohol. In all the analyzed samples of grape and plum brandies, the most abundant was isoamyl alcohol which content ranged from 50.3 to $290.7 \mathrm{mg} / 100 \mathrm{~mL}$ a.a. Comparing the results with the data from the literature, it can be concluded that the concentrations of all investigated volatile compounds in the samples of grape and plum brandies are commonly acceptable.
\end{abstract}

Keywords: Fruit Spirits, Gas Chromatography (GC), Methanol, Ethyl Acetate, Fusel Alcohols

\section{Introduction}

The Republic of Macedonia has and old and rich tradition in fruit growing and production of distilled beverages. The national brands of distilled fruit spirits are: grape brandy which is produced from grapes (Vitis Vinifera L.) crop and plum brandy which is produced from plum (Prunus) crop. The traditional method used to obtain fruit brandies is the distillation of fruit pulp in a cauldron from which the fumes are introduced through the copper tube into a coil. It is located in a large bowl with water and due to evaporation at the end of the chain the final spirit is obtained [1].

The storage and the maturing are achieved in wood barrels, stainless steel or glass recipients for at least three months. The yellow or gold-yellow color of that traditional distillate can be obtained exclusively by maturing in wood barrels (mainly the oak barrels) without any colorants or pure alcohol of the industrial origin added [2].

The preparation and fermentation of raw material, distillation technology and maturation are main factors responsible for the specific bouquet of fruit brandies [3].

Although the major physiologically active component of most alcoholic beverages is ethyl alcohol, there is a remaining fraction of highly volatile compounds like alcohols, acids, aldehydes, ketones and esters which are called congeners. Congener content of commercial alcoholic beverages differs significantly for each type of beverage, wine and beer having appreciably higher amounts than distilled spirits [4]. Even if quantitatively small, they play an important and often unnoticed role in the social use and of the alcohol abuse [5].

While thousands of different volatile congeners may be found in various drinks at one time or another, several of them have been found to be constantly present: methyl alcohol, acetaldehyde, ethyl acetate, ethyl formate and the 
small aliphatic alcohols ( $n$-propyl alcohol, isopropyl alcohol and $n$ - butyl alcohol) make up the major volatile congener content of beers, wines and distilled spirits [6].

Methanol, furfural, isobutyl alcohol and acetaldehyde have toxic potential. This is the reason why the European Commission established a maximum admissible value for methanol in fruit brandies being $10 \mathrm{~g} / \mathrm{L}$ of pure ethanol (p.e.), equivalent to $1000 \mathrm{mg} / 100 \mathrm{~mL}$ anhydrous alcohol (a.a.). In the case of ethyl alcohol of agricultural origin, the limits of these toxic compounds are more restrictive (acetaldehyde maximum $0.5 \mathrm{mg} / 100 \mathrm{~mL}$ a.a.; methanol $30 \mathrm{mg} / 100 \mathrm{~mL}$ a.a.; furfural not detectable [7].

In the industrial production of grape and plum brandies, distillation processes are well controlled, and therefore the risk for methanol presence in the final product is diminished. The industrial production of different types of spirits at Republic of Macedonia has been changed and enlarged significantly in the last decade.

The aim of this study was to compare the content of some volatile congeners as: ethyl acetate, methanol, isopropyl alcohol (2-propanol), n-propyl alcohol (propan-1-ol), isobutyl alcohol (2-methylpropan-1-ol) , n-butyl alcohol (1-butanol), isoamyl alcohol (3-methyl-1-butanol) and $n$-amyl alcohol (pentan-1-ol) in different grapes and plum brandies industrially produced at Republic of Macedonia. For that purpose we use gas chromatography (GC) with flame ionization detection (FID). For the determination of ethanol content in the spirits, we use acetonitrile (ACN) as an internal standard (IS) [8]. For the determination of ethyl acetate, methanol, isopropyl alcohol, n-propyl alcohol, isobutyl alcohol, $n$-butyl alcohol, isoamyl alcohol and $n$-amyl alcohol in spirits, we used 4-methyl-1-pentanol as an IS [7].

\section{Materials and Methods}

\subsection{Sampling}

Materials: A total of 150 samples of grape brandies (from years 2008 - 2010) and 70 samples of plum brandies (from years 2012-2014) industrially produced at Republic of Macedonia were tested to detect the presence of several volatile congeners as: ethyl acetate, methanol, isopropyl alcohol, $n$-propyl alcohol, isobutyl alcohol, $n$-butyl alcohol, isoamyl alcohol and $n$-amyl alcohol. Three different types of grape brandies were produced from the same grape cultivar. Type 1 (65 samples) was obtained after distillation of the concentrated grape juice, type 2 (55 samples) was obtained after distillation of the grape pomace and type 3 (30 samples) was obtained after distillation of wine.

Brandies were produced in pot stills (batch distillation). After distillation, brandies were aged in oak casks (single barrel aging). After a period of aging, the mature brandy was mixed with distilled water to reduce alcohol concentration and bottled.

The samples were provided by five producers located at Republic of Macedonia, who had guaranteed the authenticity of spirits.

\subsection{Chemicals}

Ethanol absolute, Acetonitrile (ACN) with a special grade for residue analysis was purchased from Sigma-Aldrich/Fluka/Riedel-de-Haen (Zwijndrecht, The Netherlands). Water was deionized then distilled from glass apparatus. Reference pure standards (chromatographic grade) of ethanol, ethyl acetate, methanol, isopropyl alcohol, $n$-propyl alcohol, isobutyl alcohol and isoamyl alcohol, and internal standard (IS) 4-methyl-1-pentanol were purchased from Sigma-Aldrich/Fluka/Riedel-de-Haen (Zwijndrecht, The Netherlands).The purity of all chemicals was above $99.9 \%$.

\subsubsection{Preparation of Standard Solutions}

\subsubsection{Preparation of Standard Solutions of Volatile Congeners (Ethyl Acetate, Methanol, Isopropyl Alcohol, N-Propyl Alcohol, Isobutyl Alcohol and Isoamyl Alcohol)}

Standard solution A. Pipette $3.0 \mathrm{~mL}$ of each analyte into a $100 \mathrm{~mL}$ volumetric flask, containing ca $60 \mathrm{~mL}$ ethanol solution to minimize component evaporation, make up to volume with ethanol solution, and mix thoroughly. Record the weight of the flask.

Standard solution B.-Pipette $3 \mathrm{~mL}$ 4-methyl-1-pentanol into a $100 \mathrm{~mL}$ volumetric flask containing ca $80 \mathrm{~mL}$ ethanol solution, make up to volume with ethanol solution, and mix thoroughly. Record the weight of the flask, the weight of internal standard added, and the total final weight of the contents.

Standard solution C.-Pipette $1 \mathrm{~mL}$ solution A and $1 \mathrm{~mL}$ solution B into a $100 \mathrm{~mL}$ volumetric flask containing ca 80 $\mathrm{mL}$ ethanol solution, make up to volume with ethanol solution, and mix thoroughly. Record the weight of the flask, each component added, and the total final weight of the contents.

Standard solution D.-Pipette $10 \mathrm{~mL}$ solution B into a100 $\mathrm{mL}$ volumetric flask containing ca $80 \mathrm{~mL}$ ethanol solution, make up to volume with ethanol solution, and mix thoroughly. Record the weight of the flask, each component added, and the total final weight of the contents.

Standard solutions used to check the linearity of response of FID.-Into separate $100 \mathrm{~mL}$ volumetric flasks containing ca $80 \mathrm{~mL}$ ethanol solution, pipette $0,0.1,0.5,1.0$, and 2.0 $\mathrm{mL}$ solution $\mathrm{A}$ and $1 \mathrm{~mL}$ solution $\mathrm{B}$, make up to volume with ethanol solution, and mix thoroughly. Record the weight of the flask, each component added, and the total final weight of the contents.

Standard solutions were stored at $<5^{\circ} \mathrm{C}$ and were prepared freshly on a monthly basis.

\subsubsection{Preparation of Ethanol Standard Solutions}

Preparation of ethanol stock standard solution $(10 \mathrm{~g} / \mathrm{L})-$ Weight $10 \mathrm{~g}$ of ethanol in $1000 \mathrm{~mL}$ volumetric flask, and dilute with distilled water to the mark.

Preparation of IS stock standard solution (10 g/L) - 
Weight $10 \mathrm{~g}$ of ACN in $1000 \mathrm{~mL}$ volumetric flask, and dilute with distilled water to the mark.

Preparation of IS working standard solution (1 g/L) Pipette $10 \mathrm{~mL}$ of stock IS solution $(10 \mathrm{~g} / \mathrm{L})$ into a $100 \mathrm{~mL}$ volumetric flask and dilute with distilled water to the mark.

Preparation of ethanol/IS working standard solutions Mix ethanol stock standard solution $(10 \mathrm{~g} / \mathrm{L})$ with ACN stock standard solution $(10 \mathrm{~g} / \mathrm{L})$ in various ratios $(15: 1,10: 1$, $5: 1,2: 1,1: 1,1: 2,1: 5,1: 10$, and 1:15).

\subsection{Instrumentation}

The major volatile components in spirits were analyzed on Shimadzu 2010 gas chromatograph (GC) equipped with an automatic liquid sampler and a flame-ionization detector (FID). Separation of the analytes was made on a polar fused silica capillary column $(30 \mathrm{~m}$ x $0.32 \mathrm{~mm}$ id. $\quad$ x $0.25 \mu \mathrm{m}$ film thickness) coated with bonded; poly(ethylene glycol), commercially available as Supelcowax obtained from Supelco (USA). The carrier gas (nitrogen) flow rate was 1.5 $\mathrm{mL}^{\prime}$ min and the split ratio was $1: 10$. The injection port was maintained at $250{ }^{\circ} \mathrm{C}$ and FID at $280{ }^{\circ} \mathrm{C}$. Oven temperature was set at $50{ }^{\circ} \mathrm{C}$ ( 5 minutes $)$ increasing for $10{ }^{\circ} \mathrm{C} / \mathrm{min}$. The final oven temperature was maintained at $200{ }^{\circ} \mathrm{C}(10 \mathrm{~min}$.$) .$

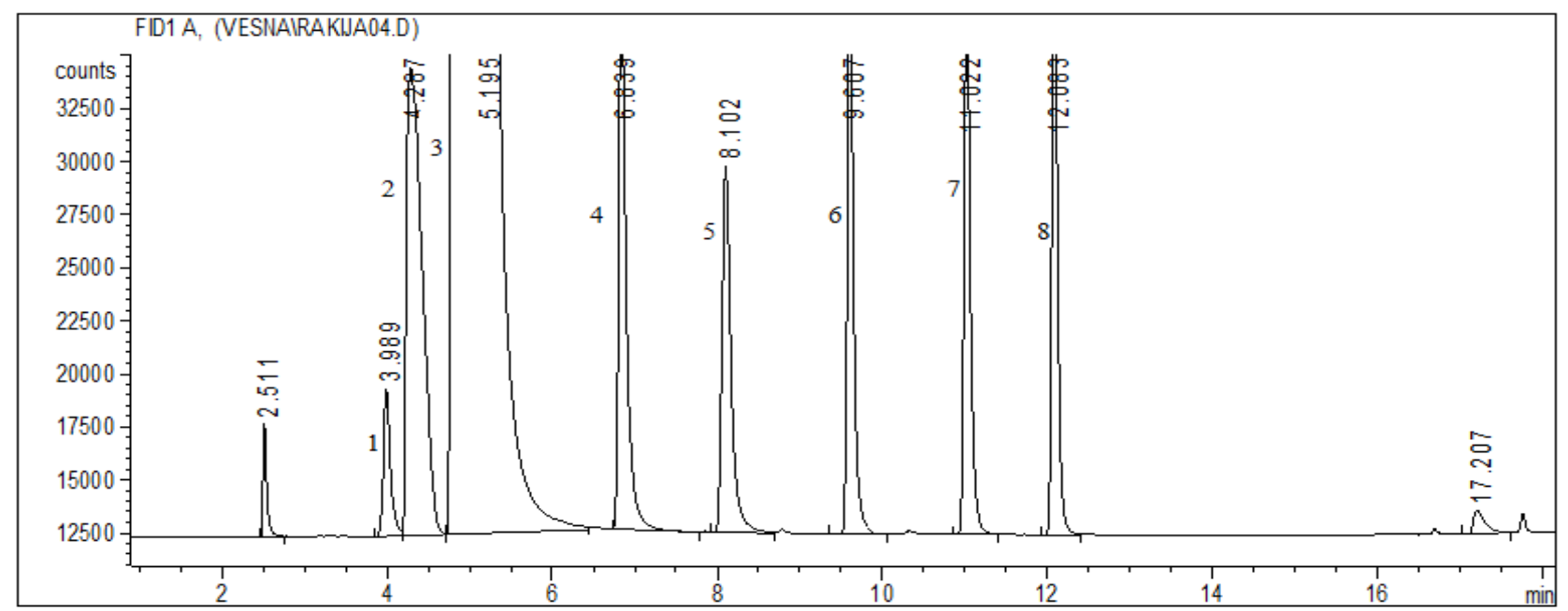

Figure 1. GC-FID chromatogram of standard solution with volatile congeners in ethanol (40:60, V/V):ethyl acetate (1), methanol (2), ethanol (3), alcohol 4), isobutyl alcohol (5), n-butyl alcohol (6), isoamyl alcohol (7) and n-amyl alcohol (8).

Qualitative identification on the analytes was based on retention time in the column and appearance of the peak signal as compared with the standard solution with known substances (Fig. 1). Retention times of tested volatile compounds are given in Table 1. For quantitative evaluation the IS method was applied. The concentration of each volatile was determined with respect to the IS from the relative response factors (RRF), which were obtained during calibration under the same chromatographic conditions as those of the sample analysis.

Table 1. Retention times $\left(R_{t}\right)$ for investigated volatile compounds.

\begin{tabular}{ll}
\hline Volatile compound & $\mathbf{R}_{\mathbf{t}}(\mathbf{m i n}) \pm \mathbf{S D}$ \\
\hline ethyl acetate & $3.989 \pm 0.009$ \\
methanol & $4.287 \pm 0.010$ \\
ethanol & $5.195 \pm 0.0012$ \\
isopropyl alcohol & $5.315 \pm 0.008$ \\
$n$-propyl alcohol & $6.839 \pm 0.010$ \\
isobutyl alcohol & $8.102 \pm 0.011$ \\
$n$-butyl alcohol & $9.607 \pm 0.012$ \\
isoamyl alcohol & $11.022 \pm 0.009$ \\
$n$ - amyl alcohol & $12.083 \pm 0.011$ \\
\hline
\end{tabular}

\subsection{Sample Preparation}

\subsubsection{Sample Preparation for Determination of Volatile Congeners}

Weigh an appropriate sealed weighing vessel and record the weight. Pipette $9 \mathrm{~mL}$ sample into the vessel and record the weight. Add $1 \mathrm{~mL}$ standard solution $\mathrm{D}$ and record the weight. Shake the sample vigorously. Transfer $2 \mathrm{~mL}$ of the sample in the auto sampler vial. $1 \mu \mathrm{L}$ of the sample was injected directly into the GC injector.

\subsubsection{Preparation of a Blank Sample}

Weigh an appropriate sealed weighing vessel and record the weight. Pipette $9 \mathrm{~mL} 400 \mathrm{~mL} / \mathrm{L}$ ethanol solution into the vessel and record the weight. Add $1 \mathrm{~mL}$ standard solution $\mathrm{C}$ and record the weight. Shake the test material vigorously. 1 $\mu \mathrm{L}$ of the sample was injected directly into the GC injector.

Quantification of volatile congeners

RRF for each congener is calculated with the equation (1):

$R R F=\frac{\text { peak area }(\text { peak height }) I S}{\text { peak area }(\text { peak height }) \text { congener }}, \frac{\gamma \text { congener }(\mu g / g)}{\gamma I S(\mu g / g)}$

Where, $\gamma$ congener represents the concentration of congener in the solution $\mathrm{C}, \gamma$ IS represents the concentration of IS in the solution C.

The concentration of each congener in the samples is calculated with the equation (2): 


$$
\gamma(\mu g / g)=\frac{\text { peak area }(\text { peak height }) \text { congener }}{\text { peak area }(\text { peak height }) I S} \cdot \frac{m I S(g)}{m \text { sample }(g)} \cdot \gamma I S(\mu g / g) \cdot R R F
$$

Where, $m$ IS represents the mass of the IS, m sample represents the mass of the sample, $\gamma$ IS represents concentration of IS in the solution D, and RRF is the relative response factor calculated from the equation above.

Results are converted from $\mu \mathrm{g} / \mathrm{g}$ to $\mathrm{mg} / 100 \mathrm{~mL}$ a.a., using the equation (3):

$$
\gamma(m g / 100 m L \text { a.a. })=\frac{\gamma(\mu g / g) \cdot S G}{\%(v / v) \cdot 100}
$$

Where, $\mu \mathrm{g} / \mathrm{g}$ is the concentration of the congener found in the sample, $\%, V / V$ is the concentration of ethanol in the sample (ethanol strength) and the SG is the specific gravity of the sample (density at $20{ }^{\circ} \mathrm{C}$ ).

\subsubsection{Sample Preparation for Determination of Ethanol}

$0.5 \mathrm{~mL}$ of sample was mixed thoroughly with $5 \mathrm{~mL}$ of $0.1 \%$ $(W / V)$ internal standard solution (equivalent to $5 \mathrm{mg}$ ). After mixing, $2 \mathrm{~mL}$ of the solution were transferred into an auto sampler vial. $1 \mu \mathrm{L}$ of the solution was injected directly into the injector of the gas chromatograph

Quantification of ethanol

A linear regression line was generated with area-under-curve (AUC) ratio of ethanol to ACN (Y axis) against the concentration ratio of ethanol to ACN (X axis). RRF of ethanol to ACN represents the slope of the regression line, as follows:

$$
R R F=\frac{(A S / W S)}{(A I S / W I S)}
$$

Where, AS represents ethanol AUC, AIS represents ACN AUC, WS represents ethanol weight (mg), WIS represents ACN weight (mg).

The ethanol content was calculated as follows:

$$
\gamma \text { ethanol }(m g / m L)=(A S / A I S) \cdot(W I S / R R F) \cdot 1 / V
$$

Where, V represents sample volume $(\mathrm{mL})$.

Results are converted from $\mathrm{mg} / \mathrm{g}$ to $\%(V / V)$ by multiplication with factor of 0.123

\subsection{Statistical Analysis}

The statistical analysis was performed using Origin software package version 8.0. The statistical significance of the difference between the data pairs for the content of volatile compounds was evaluated by analysis of variance (One-way ANOVA) followed by the Tukey test. Statistical differences were considered significant at $p<0.05$.

\section{Results and Discussion}

The results for the determination of ethanol concentrations in the fruit spirits are outlined in Table 2.

Ethanol is present in alcoholic beverages as a consequence of the fermentation of carbohydrates with yeast and is responsible for the beverage's body [3]. The ethanol concentration in different types of spirits is defined by International Regulation [7]. Its determination is part of the quality control of spirit drinks. Following this regulation, the authentic spirits made from grapes should meet the minimum limit approved for the ethanol concentration which is set from $36 \%$ to $37.5 \%(V / V)$. In all tested samples, the ethanol content was found to be in compliance with proposing Regulations [7]. Namely, the lowest mean value for the ethanol content $(38 \%, V / V)$ was found in the samples of grape brandies produced from wine distillate and the highest value $(48 \%)$ was found in the samples of plum brandy $(48 \%, V / V)$.

Table 2. Concentration of ethanol in fruit spirits.

\begin{tabular}{llll}
\hline \multirow{2}{*}{ Type of fruit brandy } & \multicolumn{3}{l}{ Ethanol concentration $(\boldsymbol{\%}, \boldsymbol{V} / \mathbf{V})$} \\
\cline { 2 - 4 } & Minimum value & Maximum value & $\begin{array}{l}\text { Mean } \\
\text { value }\end{array}$ \\
\hline Grape brandy, type 1 & 40 & 51 & 46 \\
Grape brandy, type 2 & 41 & 50 & 47 \\
Grape brandy, type 3 & 38 & 39 & 38 \\
Plum brandy & 47 & 51 & 48 \\
\hline
\end{tabular}

At the 0.05 level of significance, the analysis of variance showed that the population means for ethanol were not significantly different between the analyzed samples of grape brandy obtained after distillation of the concentrated grape juice (type 1) and grape brandy obtained after distillation of the grape pomace (type 2). This means that there was no difference observed in the ethanol content, since the sugar content of the raw material that was used in both cases was similar.

The results for the determination of volatile congeners of fruit spirits are shown in Table 3 .

Table 3. Concentration of volatile congeners in fruit spirits.

\begin{tabular}{lllll}
\hline Type of volatile compound & Grape brandy type 1 & Grape brandy type 2 & Grape brandy type 3 & Plum brandy \\
\hline \multicolumn{1}{l}{ Minimum value - Maximum value (Mean value), $\mathbf{~ m g / 1 0 0 ~} \mathbf{~ m L}$ a.a. } & & & \\
\hline ethyl acetate & $5.2-255.3(70.5)$ & $80.1-158(107.2)$ & $35-240.3(88.3)$ & $48-454(143.5)$ \\
methanol & $3.5-883(523.5)$ & $38.5-835(598)$ & $44-405(171)$ & $564-990(892)$ \\
isopropyl alcohol & $10.3-17.2(11.8)$ & $11.2-19.4(17.6)$ & $7-11(9.1)$ & $12.2-26.5(14.4)$ \\
$n$-propyl alcohol & $4.1-90.5(30.5)$ & $31.3-49.8(44.2)$ & $29.3-48.6(30.1)$ & $22-305(124)$ \\
isobutyl alcohol & $7.2-60.3(38.4)$ & $1.5-110.5(41.3)$ & $35.5-48.2(34.5)$ & $14.5-55(38)$ \\
$n$-butyl alcohol & $1.2-5.2(4.6)$ & $2.9-3.5(3.1)$ & $1.0-2.3(1.1)$ & $4.5-12(7)$ \\
isoamyl alcohol & $50.3-290.7(180.5)$ & $53.8-280.9(180.6)$ & $123-133(126.4)$ & $101-141(115)$ \\
$n$ - amyl alcohol & $0.93-3.7(2.4)$ & $1.4-4.1(3.1)$ & $0.50-2.4(1.4)$ & $9.2-14(12.5)$ \\
\hline
\end{tabular}


Esters are very important compounds due to their particular contribution to flavour and aroma, since they have the lowest organoleptic threshold [9]. The quantity of this compound presented in the final product can vary widely, since it is synthesized from acetic acid and ethanol [10]. High concentrations of ethyl acetate are indicative of prolonged storage of the raw material and probable acetic bacteria spoilage. Concerning ethyl acetate, many authors have documented high variability $[11,12]$. The mean values of the concentration of ethyl acetate for tested samples ranged from $5.2 \mathrm{mg} / 100 \mathrm{~mL}$ a.a. for grape brandy produced from grape juice (type 1) to $454 \mathrm{mg} / 100 \mathrm{~mL}$ a.a. for plum brandy (Table 4). The results obtained for the content of ethyl acetate in plum brandy were in correlation with those of Winterova et al., where the content of ethyl acetate in the samples of plum brandy ranged from $56.3 \mathrm{mg} / 100 \mathrm{~mL}$ a.a to 236/100 $\mathrm{mL}$ a.a [13]. Comparing these results, it can be concluded that the concentrations of ethyl acetate found in these samples are commonly acceptable.

Methanol is not a by-product of yeast fermentation but originates from pectin in the mist and juice when grapes and fruits are macerated. In general, the methanol content of commercial alcoholic beverages is fairly small, except in those produced from grapes in prolonged contact with enzyme pectin methyl esterase and in some brandies produced from stone fruits, such as cherries and plums. The methanol concentration is suitable for proving the authenticity of fruit spirits [14].

Because its toxicity for the health of humans current European Union (EU) regulations limit naturally occurring methanol to below $1000 \mathrm{mg} / 100 \mathrm{~mL}$ a.a. [7]. The determination of methanol content is a part of the quality control of spirit drinks. The methanol content in the analyzed samples ranged between $3.5 \mathrm{mg} / 100 \mathrm{~mL}$ a.a. for grape brandy produced from grape juice to $990 \mathrm{mg} / 100 \mathrm{~mL}$ a.a. for plum brandy. The obtained results for methanol content in all tested samples were bellow established legal limits, meaning that the raw material was fermented with great sensitivity and very good distillation procedures were performed. The highest methanol content was found in the samples of plum brandy, which is mainly due to the higher content of pectin in the raw material.

Higher alcohols are characteristic components which are metabolised from amino acids by yeasts during alcoholic fermentation of fruits and other raw materials. The amounts of these compounds depend on the quantity of amino acids in fruits. Higher alcohols have a significant impact on the flavour of alcoholic beverages [4, 5]. But, except having a significant impact on the flavour of alcoholic beverages higher alcohols are mildly toxic. Wencker et al. showed that $n$-butyl alcohol is a strongly discriminating parameter for the fruit spirits [15]. In their investigations of Australian and imported brandies Hogben and Mular found out that the isoamyl alcohol vs. isobutyl alcohol content and the isobutyl alcohol vs. $n$-propyl alcohol content is one of the several criteria for characterization the authenticity of brandies [14].

In our investigation we found that the most important higher alcohols of grape and plum brandies are: $n$-propyl alcohol, isobutyl alcohol and isoamyl alcohol. In all the analyzed samples of grape and plum brandies, the most abundant was isoamyl alcohol which content ranged from 50.3 to $290.7 \mathrm{mg} / 100 \mathrm{~mL}$ a.a. According to Pietruszka et al. in the spirits obtained from ray mashes, isoamyl alcohol has the highest contribution [16]. According to Tešević et al. the concentrations of isoamyl alcohol in the distillate obtained from cornelian cherry ranges from 148.9 to 263.5 $\mathrm{mg} / 100 \mathrm{~mL}$ a.a, which is higher than levels in spirits obtained from grapes and plums [17].

At the 0.05 level of significance, the analysis of variance showed that the population means for isoamyl alcohol were not significantly different between the analyzed samples of grape brandy obtained after distillation of the concentrated grape juice (type 1) and grape brandy obtained after distillation of the grape pomace (type 2), which means that there were not differences observed during alcoholic fermentation of fruits, since the row material used in both cases was similar.

Among the investigated higher alcohols, the lowest content in all tested samples were found for $n$-amyl alcohol with mean values ranging from $1.4 \mathrm{mg} / 100 \mathrm{~mL}$ a.a for grape brandy produced from wine distillate to $14 \mathrm{mg} / 100 \mathrm{~mL}$ a.a. for plum brandy (Table 4). The content of $n$-butyl alcohol was also found to be low in all tested samples, ranged from 1 $\mathrm{mg} / 100 \mathrm{~mL}$ a.a. for grape brandy produced from wine distillate to $12 \mathrm{mg} / 100 \mathrm{~mL}$ a.a for plum brandy. According to the investigations of Winterove et al., the higher alcohols most frequently found in low concentrations in fruit spirits were $n$-butyl alcohol and isobutyl alcohol [13]. They found the lowest values measured for $n$-butyl alcohol in sweet cherry and sour cherry brandies $(0.5-3.1 \mathrm{mg} 100 \mathrm{~mL}$ a.a.). Comparing these results, it can be concluded that the concentrations of higher alcohols found in our samples of grape and plum brandies are commonly acceptable.

\section{Conclusions}

The findings presented in this paper provide a picture for the major volatile compounds that were found in fruit spirits produced industrially from grape juice, grape pomace, wine distillate and plums. The producers, as well as, the raw material, originated from the Republic of Macedonia.

In general, the compounds identified in major quantities in tested grape and plum brandies are similar to those present in other distilled spirits. The major volatile compounds that can pose health hazards such as methanol, ethyl acetate, and higher alcohols were found at levels lower than those established by the EC. The most abundant higher alcohol in all tested samples was found to be isoamyl alcohol, which is line with the literature data. Comparing the results with the data from the literature, it can be concluded that the concentrations of all investigated volatile compounds in the samples of grape and plum brandies are commonly acceptable. 


\section{References}

[1] N. Pomohaci, I. Cioltean, L. Visan, F. Radoi, "Tuica and natural brandies". Ed. Ceres. Bucharest, 2002J. Clerk Maxwell, A Treatise on Electricity and Magnetism, 3rd ed., vol. 2. Oxford: Clarendon, 1892, pp.68-73.

[2] S. Stanimirović and D. Stanimirović, "Bromatologija", Zavod za Udzbenike i Nastavna Sredstva, Beograd, SFRJ, 1982.

[3] H. F. A. Scanavini, R. Ceriani and A. J. A. Meirelles, "Cachaça distillation investigated on the basis of model systems", Braz. J. Chem. Eng. vol. 29 (2), pp. 429-440, 2012.

[4] A. Jung, H. Jung, W. Auwarter, S. Pollak, A. M. Farr, L. Hescer and A. Schiopu, "Volatile congeners in alcoholic beverages: analysis and forensic significance". Romanian Society of Legal Medicine, vol. 18, pp.265- 270, 2010

[5] W. Bonte, "Begleitstoffe alkoholischer Getranke: Biogenese, Vorkommen, Pharmakologie, Physiologie und Begutachtung", Verlag Max Schmidt - Romhild, Lubeck, 1987.

[6] Z. Kucuk and K.Ceylan, "Potential Utilization of Fusel Oil: A Kinetic Approach for Production of Fusel Oil Esters through Chemical Reaction”. Turk. J. Chem., vol. 22, pp. 289-300, 1998.

[7] EEC, Council Regulation No. 110/2008 of 15 January 2008, "Laying down general rules on the definition, description and presentation of spirit drinks", Off. J. Eur. Union, L 39/16, pp. 17-18, 2008.

[8] M. L. Wang, Y. M. Choong, N. W. Su and M. H. Lee, "A rapid method for determination of ethanol in alcoholic beverages using capillary gas chromatography", Journal of Food and Drug Analysis, vol. 11, (2), pp. 133-140, 2003.

[9] C. M. Ramsay and D. R. Berry, "The effect of temperature and $\mathrm{pH}$ on the formation of higher alcohols, fatty acids and esters in malt whisky fermentation”, Food Microbiology vol. 1, pp. 117-125, 1984.
[10] M. L. Silva, A.C Macedo and F.X G Malcata, "Steam distilled spirits from fermented grape pomace", Food Sci. Technol. Int. vol. 6, pp. $285-300,2000$.

[11] M. L. Silva, F. X. Malcata and G. De Revel, "Volatile content of grape marcs in Portugal. J. Food Compos. Anal. vol. 9 (1), pp. $72-80,1996$.

[12] A.A. Apostolopoulou., I. Flouros, P.G Demertzis and K Akrida-Demertzi, "Differences in concentration of principal volatile constituents in traditional Greek distillates", Food Cont. vol. 16, pp. 157-164, 2005.

[13] R. Winterove., R Mikulhkove, J. Maceč and P Havelec, "Assessment of the Authencticity of Fruit Spirits by Gas-Chromatography and Stable Isotope ratio Analysis", Czech J. Food Sci., vol. 26 (5), pp. 368-375, 2008.

[14] R. Hogben and M. Mular, "Major congeners of Australian and imported brandies and other spirits as indicator of authenticity", Journal of the Science of Food and Agriculture vol. 27 (12), pp. 1108-1114, 1976.

[15] D.Wencker, M.Louis, G. Nomura and M.Hasselmann "Etude de la Fraction"Alcools Superieurs Methanol" de diverses Eaux-de-vie II -Distribution des differents alcohols en function de l'origine botanique des fruits". Annales des Falsifications et de l' Expertise Chimique, vol. 74, pp. 487 499, 1981.

[16] M Pietruszka, K. Pielech-Przybylska and J.S. Szopa, "Synthesis of higher alcohol during alcoholic fermentationof rye mashes". Scientific Bulletin of the Technical University of Lodz, Food Chemistry and Biochemistry, vol. 1081 (74), pp. 51-64, 2010.

[17] V. Tešević, N. Nikičević, A. Jovanović, S. Milosavlevjević, D. Bajić, V. Vajs, I. Vučković, Lj. Vujisić, I. Đordević, M. Stanković, M. Veličković, "Characterization of volatile compounds of Drenja, an alcoholic beverage obtained from the fruits of cornelian cherry", J. Serb. Chem. Soc., vol. 74, pp. 117-128, 2009. 